\title{
CIDADES EDUCADORAS, DESENVOLVIMENTO E SUSTENTABILIDADE
}

\author{
EDUCATING CITIES, DEVELOPMENT AND SUSTAINABILITY
}

\author{
Claudison Vieira de Albuquerque ${ }^{1}$ \\ António Manuel Rochette Cordeiro ${ }^{2}$ \\ Joaquim Luis Medeiros Alcoforado ${ }^{3}$ \\ Marcos Alexandre de Melo Barros ${ }^{4}$
}

RESUMO: $O$ embate entre os conceitos de crescimento e desenvolvimento econômico, desenvolvimento sustentável e desenvolvimento humano, associado às políticas públicas de melhorias na oferta de bens e serviços, como universalização do ensino, do acesso à saúde, das melhorias estruturais das cidades (saneamento, urbanização e mobilidade), foram temas que compuseram as agendas dos países na segunda metade do século 20 e início do século 21. Para isso, a construção de cidades educadoras e inteligentes tem sido uma tendência mundial, ainda que pouco implementada, uma vez nela se coaduna os princípios básicos de desenvolvimento e sustentabilidade.

Palavras- chaves: Desenvolvimento Humano, Cidades Educadoras, Sustentabilidade.

ABSTRACT: The clash between the concepts of growth and economic development, sustainable development and human development, associated with public policies for improvements in the offer of goods and services, such as universal education, access to health, structural improvements in cities (sanitation, urbanization and mobility), were themes that made up the countries' agendas in the second half of the 2oth century and the beginning of the 2ist century. For this purpose, the construction of educating and intelligent cities has been a worldwide trend, albeit little implemented, since it basic principles of development and sustainability.

Keywords: human development, educating cities, sustainability.

${ }^{1}$ Centro de Estudos Interdisciplinares do Século XX- Universidade de Coimbra. Doutorando em Estudos Contemporâneos pelo Centro de Estudos Interdisciplinares do Século XX da Universidade de Coimbra e Secretário de Educação do Município de Feira Nova-PE. Lattes:http://lattes.cnpq.br/8931663163707550 Orcid: https://orcid.org/oooo-0oo2-I887-42I E-mail: claudisonalbuquerque@gmail.com.

${ }^{2}$ Doutor em Geografia e Professor da Universidade de Coimbra no Departamento de Geografia, do Programa de Mestrado e Doutorado do Centro de Estudos Interdisciplinares e de Arquitetura e Urbanismo da Universidade de Coimbra. Orcid: https://orcid.org/oooo-ooo2-8648-3204. Lattes: http://lattes.cnpq.br/7823977679438842.E-mail: rochettecordeiro@fl.uc.pt.

3 Doutor em Ciências da Educação pela Universidade de Coimbra. É Professor na Faculdade de Psicologia e de Ciências da Educação da Universidade de Coimbra, do Programa de Mestrado e Doutorado do Centro de Estudos Interdisciplinares e de Ciências da Educação da Universidade de Coimbra.Lattes: http://lattes.cnpq.br/8528377297670214. Orcid: https://orcid.org/oooo-ooo3-4425-70Ir. E-mail: lalcoforado@fpce.uc.pt.

4 Doutor em Ensino das Ciências pela Universidade Federal Rural de Pernambuco (UFRPE) e Professor do Centro de Educação da UFPE e do Programa de Mestrado em Educação Matemática da UFPE-Caruaru. Lattes:http://lattes.cnpq.br/804653315353126r. Orcid: https://orcid.org/oooo-ooo2-2176-7628. E-mail: marcos@marcosbarros.com.br. 


\section{INTRODUÇÃO}

Muito tem se discutido o conceito de desenvolvimento, considerando nesse debate uma visão muito mais ampla e mais alargada do seu significado, não se limitando apenas ao conceito do ato de evoluir, de sair de um ponto considerado inferior, depreciativo e negativo para um ponto de avanços, melhorias, superioridade e positividade.

Essa discussão ganhou mais fôlego e tem ocorrido desde a década de 1990 do século 20, quando foram abordadas a colaboração e o papel das cidades educadoras nesse processo de desenvolvimento, bem como foram adotadas ações no sentido construir diretrizes para implementação destas cidades, cujo principal objetivo é proporcionar o desenvolvimento integral dos que nela habitam.

Neste trabalho será discorrido de forma mais aprofundada esses conceitos nas diversas áreas do desenvolvimento e discutirá também sobre as cidades educadoras, sendo estruturado em quatro partes. O ponto I trará de a introdução, situando o que se propõem neste trabalho. No ponto 2 será definido os conceitos de desenvolvimento humano, sustentável e econômico e a evolução desses conceitos. No ponto 3, serão levantados os conceitos de cidades educadoras e inteligentes, qual o seu papel e como elas podem colaborar com o processo de desenvolvimento e por fim, o ponto 4 serão feitas as considerações finais deste trabalho.

\section{Conceitos de Desenvolvimento}

Há pelo menos 6o anos a comunidade acadêmica, em especial a área das humanidades vem se debruçando para modular o conceito de desenvolvimento, mas, nos últimos 30 anos isso tem ganhado uma dimensão muito maior. Esse aprofundamento permitiu que o conceito conhecesse várias versões, como afirma Amaro (2015, p. 2).

O conceito de desenvolvimento nos últimos 30 anos tornou-se mais complexo e menos linear na sua concepção e aplicação. Essa complexidade foi enriquecida pela contribuição de várias disciplinas e pelas experiências de várias práticas, tornandose, por seu turno, portadora de múltiplos desafios, quer no que se refere às abordagens interdisciplinares que exige, quer no que respeita às estratégias e aos métodos de intervenção que implica.

Vários fatores e fenômenos surgidos durante a segunda metade do século 20 e início do 2I, contribuíram para que esse conceito tivesse uma ampliação no seu leque de significados. A queda do Muro de Berlim, reunificando a Alemanha Oriental a Ocidental em 1989; o fim do Regime Socialista em I991; o surgimento de um novo grupo de países que se colocam no cenário econômico mundial como industrializados, denominados de países emergentes, mas com grandes desafios a serem enfrentados; a formação de blocos econômicos em diversos continentes, a exemplo do NAFTA, União Europeia, Mercosul, etc.; a comprovação do aquecimento global através da emissão de carbono, advindo dos processos de desmatamento e queimadas, da utilização dos combustíveis 
fósseis; e a consolidação dos direitos humanos, através de tratados internacionais, visando o fim da mão de obra infantil e escrava, da extinção do tráfico de pessoas, da redução da fome, acesso a saúde e educação, entre outros aspectos que estão posto nas ODS, implementados pela ONU em 2015 e tendo mais de 150 países como signatários.

\section{I.I Desenvolvimento Econômico}

Na década de 90 do século XX, esse foi um dos temas mais discutidos no meio acadêmico, em especial na Sociologia, Economia e demais área das humanidades, pelo fato do conflito ou não, existente entre crescimento econômico e o desenvolvimento econômico.

Este conceito de desenvolvimento econômico começa a ser debatido no fim do século XIX e início do século XX, com A Teoria do Desenvolvimento Econômico de Schumpeter (1934), mas, é no fim da segunda guerra mundial que se estendeu de 1939 a 1945 com "Os acordos de Bretton Woods", que ela ganha mais espaço, pois com o fim do período bélico os países precisavam dá respostas as demandas que os assolavam e assolam ainda em muitos deles (guerra, desemprego, miséria, discriminação racial, desigualdades políticas, econômicas, etc.). (GASPAR, 2015).

Essas intenções de avanços se deram através dos protocolos assinados já em 1945 na Conferência de São Francisco - EUA, através da criação das Organizações das Nações Unidas

(ONU). Os vários departamentos e setores que compõem o organograma da ONU, cuja abrangência contempla os mais variados programas, como é o caso da FAO, UNICEF, OMS, UNESCO, PNUD, Conselho de Segurança, Corte Internacional de Justiça, entre outros dispositivos, permitiram que os países construíssem meios que possibilitassem a redução dos problemas citados no parágrafo anterior.

Para Furtado (1999, p. I15-I16) o desenvolvimento econômico é o fluxo de renda real, ou seja, o aumento da quantidade de bens e serviços por unidade de tempo que se põem a disposição da coletividade. Reforça ainda que tais fenômenos estão ligados as características de cada país, ou seja, da junção dos recursos naturais, mão de obra especializada, extensão territorial, mercado consumidor, etc., que colaboram de forma direta para a consolidação do seu crescimento.

Se esse desenvolvimento não contribuir na formação integral do homem, no conjunto de suas necessidades básicas e que não lhe garantam ascender a outros níveis sociais, haverá apenas crescimento econômico e não desenvolvimento econômico. (SEN, 20oo). 


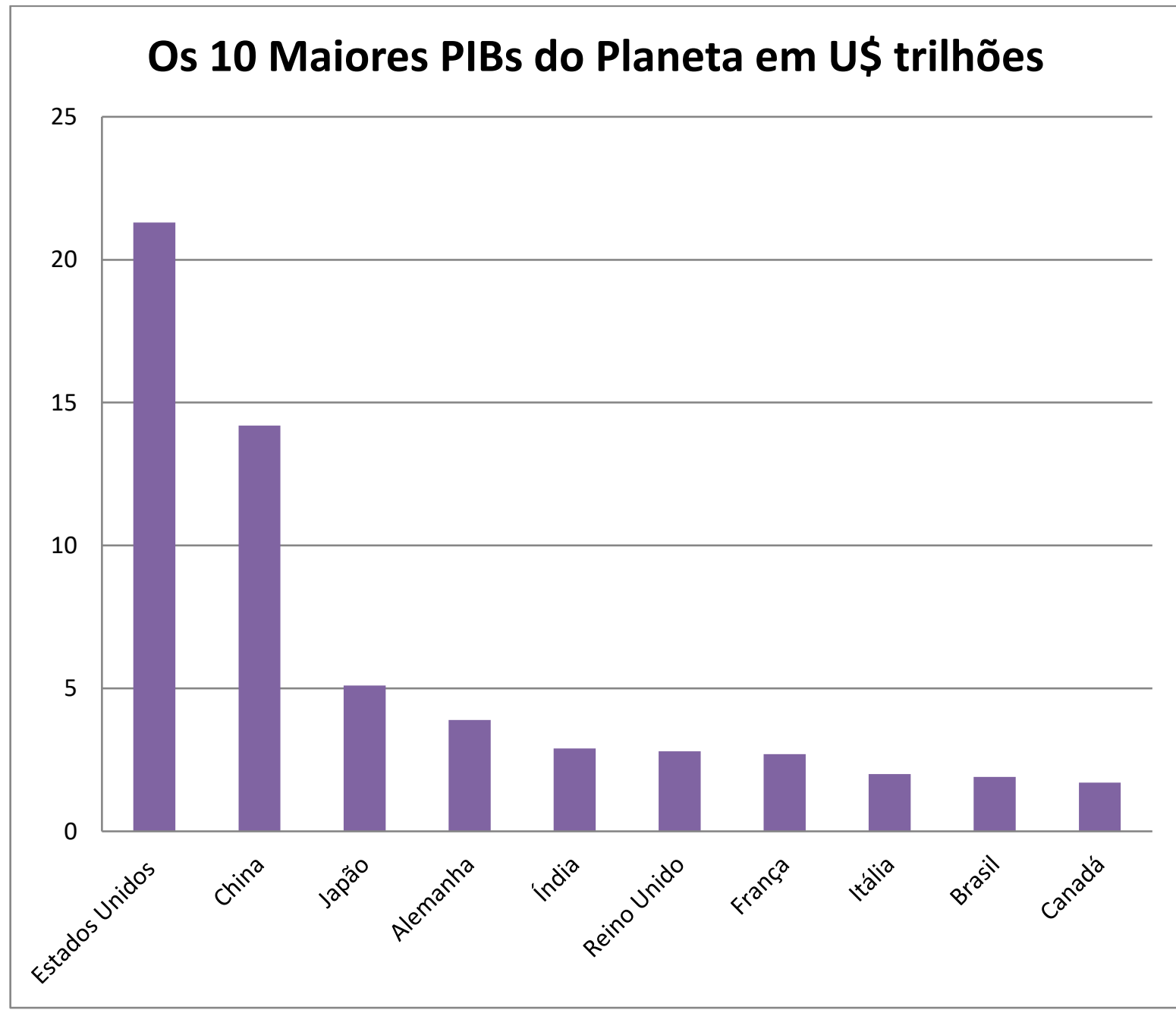

Fonte: Focus Economics, 2019.

É importante observar que o crescimento econômico não está necessariamente ligado ao desenvolvimento econômico. O gráfico mostra que apesar da pujança do Produto Interno Bruto dos dez países mais ricos do mundo, apenas um, (Alemanha) figura entre os cinco mais ricos e também entre os cinco mais desenvolvidos, como pode ser observado no gráfico I. Na proporção que vai se baixando o número do ponto de corte, o abismo se eleva ainda mais, pois apenas um país, no caso a Alemanha de novo, aparece entre os que dentre as dez maiores economias do mundo, também se posiciona entre os io mais desenvolvidos do planeta. A primeira economia do mundo (Estados Unidos da América) e a terceira maior economia (Japão) aparecem respectivamente na $15^{\underline{a}}$ e $19^{\underline{a}}$ posição. 


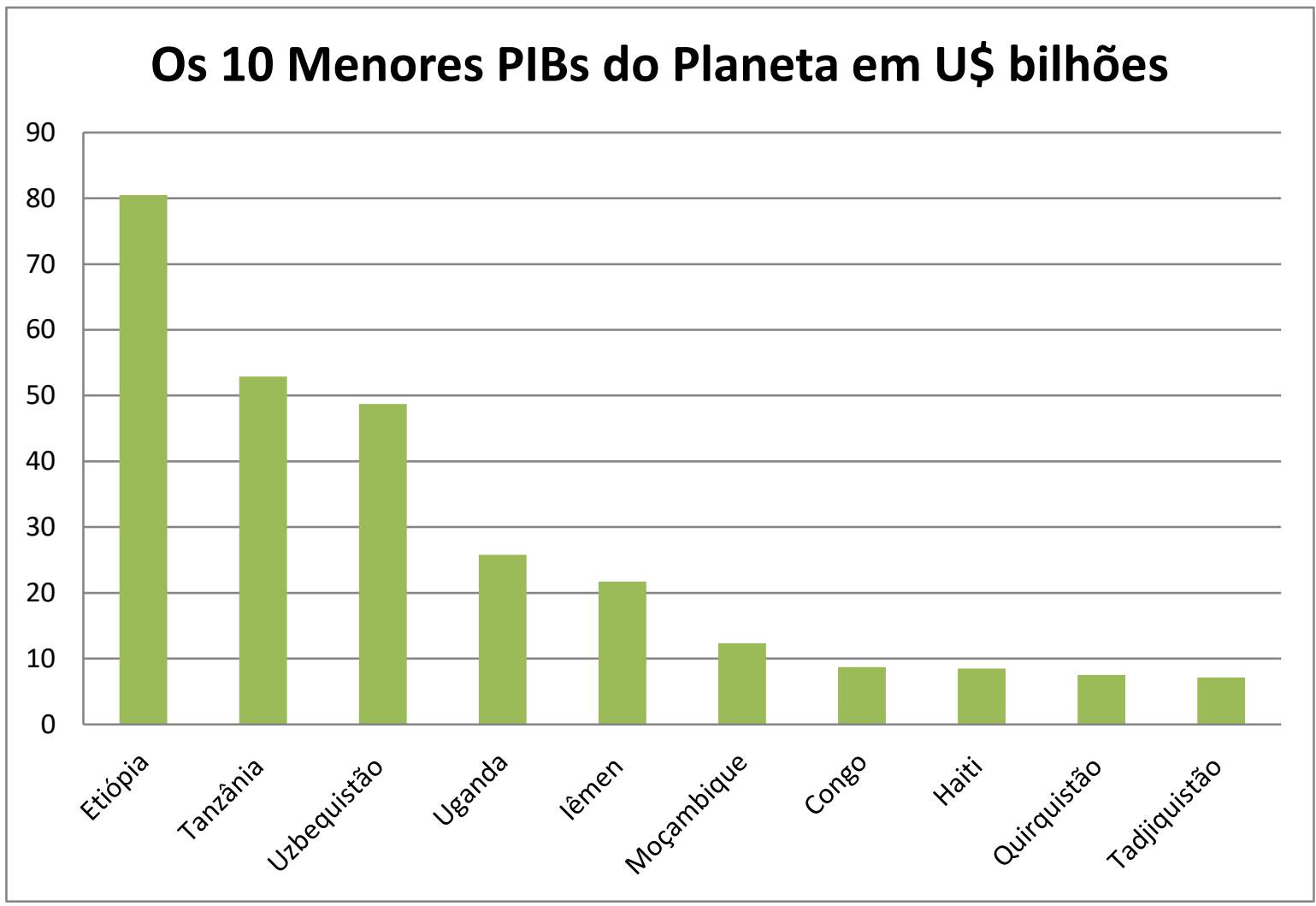

Fonte: Focus Economics, 2019.

A mesma análise pode ser observada entre os países mais pobres, pois da mesma forma que o fato de ser rico não os condiciona a estarem entre os mais desenvolvidos, não necessariamente os que possuem os menores PIBs são os que aparecem entre os menores níveis de desenvolvimento. Entre os dez países com os menores PIBs do planeta, apenas o Haiti figura ao mesmo tempo entre os que tem baixo crescimento econômico e desenvolvimento econômico.

Porém, nessa análise se faz necessário considerar vários fatores nesse processo (dimensão territorial, tamanho da população, questões geopolíticas, etc.), porém, o que se percebe às vezes é que os modelos pensados e adotados por alguns líderes desses países, nem sempre estão voltados prioritariamente para o bem estar de sua população, ou seja, a priorização do Estado de Providência ou Welfare States. O não reconhecimento do aumento do aquecimento global e a saída da Convenção de Paris por parte dos Estados Unidos da América, dentre outras medidas, é um exemplo clássico dessas decisões equivocadas e que em nada colaboram no avanço dos parâmetros do desenvolvimento econômico. Percebe-se que tais práticas têm sido utilizadas como exemplo e tem se estendido a outros líderes globais, a exemplo do Brasil. 


\section{I.2 Desenvolvimento Sustentável}

Logo após a Segunda Guerra Mundial, os chamados países do norte ou industrializados iniciaram seu processo de retomada de crescimento. A reconstrução das cidades e indústrias, o suprimento das demandas internas, a busca de novos mercados, os financiamentos, entre outros aspectos balizaram praticamente as duas décadas seguintes a guerra.

Até o final da década de 60 do século 20, praticamente não se discutia o modelo de exploração dos recursos naturais. Acreditava-se na "infinitude" desses recursos e que abastecer e suprir as suas demandas internas e buscar novos mercados era o mote a ser tocado. Apenas em 1972, com a Conferência de Estocolmo é que se iniciaram ainda de forma insipiente a buscar meios que pudesse encontrar um ponto de equilíbrio entre o crescimento econômico e a sustentabilidade do planeta. $\mathrm{Na}$ conferência estavam presentes nas discussões mais de 400 instituições governamentais e não governamentais e teve participação de II3 países.

Alguns países industrialmente desenvolvidos assumiram compromisso de buscar meios que possibilitassem o uso consciente dos recursos naturais, adotando inclusive práticas até então desconhecidas ou pouco utilizadas, como é o caso do reuso de vários insumos. Criaram comitês para discutirem meios de redução da emissão de poluentes, bem como da otimização desses recursos. Isso implicaria em uma possível diminuição no ritmo da produção industrial, conforme pode ser constatado no gráfico de número três, localizado na página 7 , mas que seriam compensadas com o aumento no setor terciário.

Por outro lado, os países subdesenvolvidos, mas que tinha na produção industrial uma expressividade econômica considerável, como era o caso do Brasil, México, Rússia, China, Índia e outros, apesar de participarem da conferência, não foram receptivos as medidas, uma vez que era na indústria que vislumbravam a possibilidade de se firmarem no mercado global. $O$ desenvolvimento a qualquer custo era a bandeira levantada por essas nações.

Ainda assim, mesmo com a desaceleração dos países do norte, os emergentes mantiveram um padrão de crescimento industrial em um ritmo maior que os demais, puxados em especial pela China, que crescia em média 10\% ao ano por aproximadamente três décadas, podendo se observadas variações na participação do PIB da indústria no PIB global dos países, conforme informações contidas no gráfico 3 . 


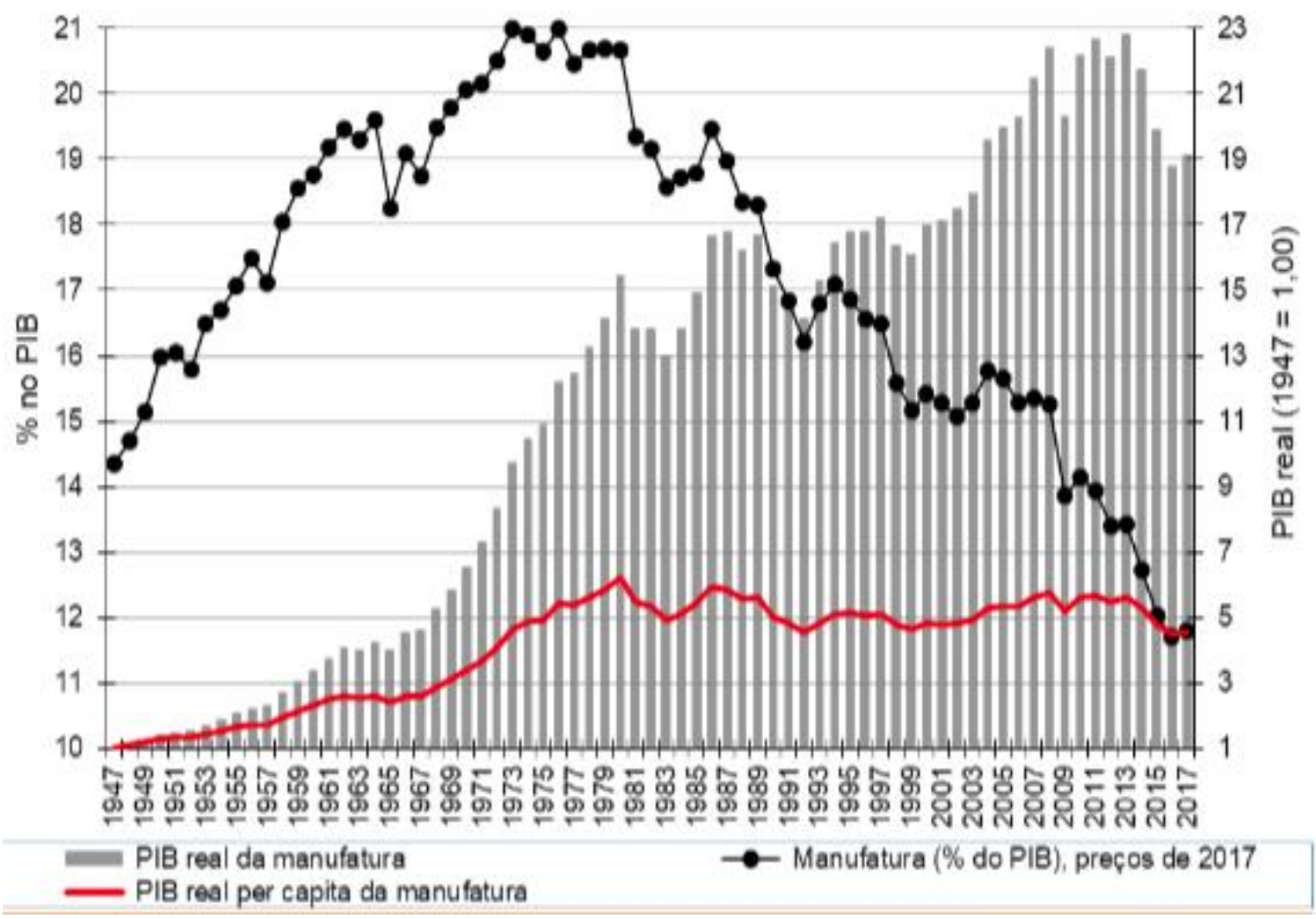

Fonte: Focus Economics, 2019.

Ainda na temática do desenvolvimento sustentável, em 1979 em Genebra ocorreu a Primeira Conferência Mundial sobre o clima, organizada pela OMM (Organização Meteorológica Mundial), reuniu cientistas e especialistas de 53 países e 24 organizações internacionais. Em 1988 a ONU cria o Painel Intergovernamental Sobre Mudanças Climáticas, órgão que sintetiza todas as informações sobre o clima mundial, sendo um órgão aberto a todos os países membros da ONU. O IPCC se debruça em informações de pesquisas recentes sobre o aquecimento global.

Em 1992 no Rio de Janeiro, foi realizado a ECO 92, primeiro encontro global organizado pela ONU sobre o clima. Nele foram dados os primeiros passos para a construção de um tratado internacional vinculante a todos os países membros. Reuniu chefes e representantes de estados de 172 países e foi formada a Convenção-Quadro das Nações Unidas Sobre o Clima - UNFCCC. Em 1994 essa convenção entra em vigor com um quadro de 196 países, divididos em três anexos, conforme figura a seguir: 
Figura I - Divisão dos Países na UNFCCC.

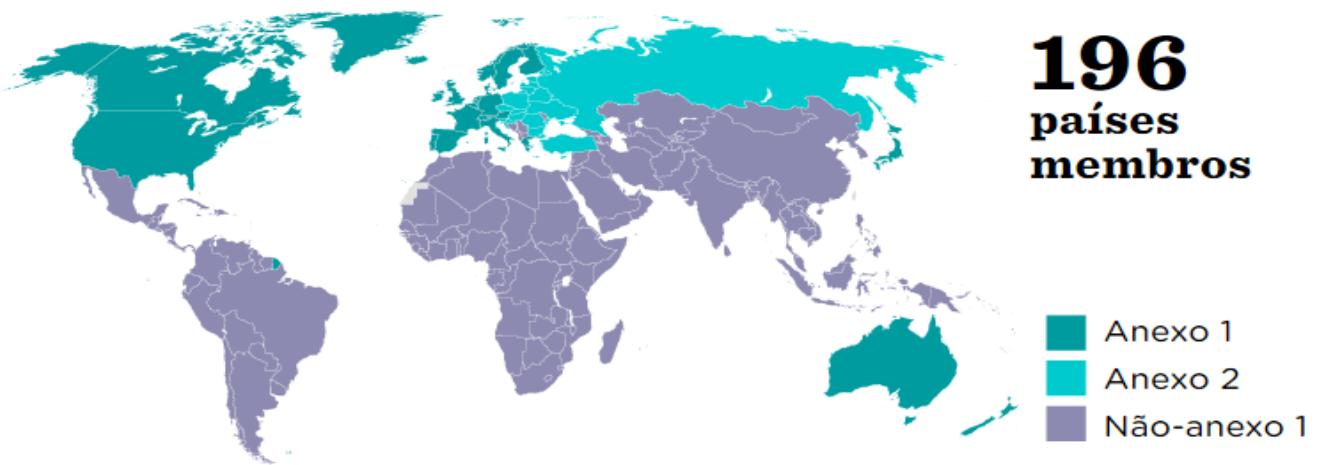

Fonte: Nexojornal, 2017.

O Anexo I é formado por um grupo de 43 países industrializados, responsáveis históricos pela maior quantidade de emissão de gases de efeito estufa. Os que compõem o anexo 2 é formado por 24 nações que também fazem parte do Anexo i e tem o papel de auxiliar os países em desenvolvimento a se adaptar às mudanças climáticas e tecnologias sustentáveis. Por fim, os do anexo 3 são países "em desenvolvimento" e que devem se voluntariar para fazerem parte do Anexo I no futuro, (ONU, 2019).

Em 1997 surge o Protocolo de Kioto, nele surgem metas e objetivos a serem alcançadas no combate aos gases de efeito estufa. Ele entra em vigor de forma definitiva em 2005 , ratificado por 192 países. Entre a assinatura do Protocolo de Kioto e sua implementação, ocorreu em 2002 o chamado Rio+ro e a Declaração de Joanesburgo. Nele foram endossados os documentos oriundos dos encontros anteriores. Foi também nesse encontro que surgiu o que pode ser chamado de primeira baixa para os anseios mundiais sobre o clima, quando os Estados Unidos da América não comparece ao encontro.

Após a implementação do Protocolo de Kioto em 2005, houve ainda vários outros encontros, como a Declaração de Copenhague em 2009, mas que por não ter sido aprovada de forma consensual, não teve status de protocolo. Em zoro ocorreu a Declaração de Cancun, em 2oII a Plataforma de Durban e em 2012 a Emenda de Doha.

Em 2015 ocorre o Acordo de Paris, substituto do Protocolo de Kioto e que tem adesão de 169 países. Ele não é vinculativo e busca a adesão ao acordo de forma voluntária dos países membros. Entra em vigor em 2017, mas nesse mesmo ano, é informado que a maior economia do mundo se retiraria do acordo a partir de novembro de 2020 .

Os desenhos e desdobramentos de todos esses protocolos, acordos e tratados objetivavam formar um conjunto de ações que pensasse em construir um modelo de desenvolvimento sustentável, que agregasse o crescimento econômico e desenvolvimento, sem comprometer a vida do e no planeta. 
A esse modelo de desenvolvimento dá-se o nome de desenvolvimento sustentável, ou seja, um desenvolvimento capaz de suprir as necessidades da geração atual, sem comprometer a capacidade de atender as necessidades das futuras gerações (ONU 2019).

\subsection{Desenvolvimento Humano}

O conceito de desenvolvimento humano, segundo a ONU, é um processo de ampliação das escolhas das pessoas para que elas tenham capacidades e oportunidades para serem aquilo que desejam ser. Essa quantificação do desenvolvimento é aferida através de vários elementos que quando reunidos, mensuram o quanto o homem pode ser/estar mais ou menos desenvolvido.

O equipamento utilizado para esta quantificação, denominado de IDH - Índice de Desenvolvimento Humano, sendo o,350 a menor pontuação que um ser humano pode obter e I,ooo a maior obtida. Os elementos que compõem essa medição são: Uma vida longa e saudável (Expectativa de vida ao nascer); $\mathrm{O}$ acesso ao conhecimento (Anos Médios de Estudo e Anos Esperados de Escolaridade) ; e Um padrão de vida decente (PIB - PPC) per capita.

Esse parâmetro varia entre IDH muito alto, sendo aqueles que pontuam acima dos o,8oo. Os altos que vão de o,70o a 0,799. Os médios que vão o,555 a o,699 e os que vão de 0,350 a o,544 são considerados baixos. Porém, há países que não são pontuados, pois não disponibilizam seus dados. Segue tabela com os cinco melhores e os cinco piores resultados, conforme metodologia da ONU/PNUD. (2019).

Tabela I: O Ranking do IDH-PNUD 2019.

\begin{tabular}{|c|c|c|}
\hline Posição & País & Pontuação \\
\hline $\mathrm{I}^{\mathrm{o}}$ & Noruega & o, 953 \\
\hline $2^{\circ}-$ & Suíça & o, 944 \\
\hline $3^{\mathrm{o}}$ & Austrália & o, 939 \\
\hline $4^{\circ}$ & Irlanda & 0,938 \\
\hline $5^{\circ}$ & Alemanha & 0,936 \\
\hline $185^{\circ}$ & Burundi & 0,404 \\
\hline $186^{\circ}$ & Chade & 0,402 \\
\hline $187^{\circ}$ & Sudão do Sul & o, 396 \\
\hline $188^{\circ}$ & República Centro-Africana & 0,353 \\
\hline $189^{\circ}$ & Níger & 0,352 \\
\hline
\end{tabular}

Fonte: PNUD, 2019.

Ao se analisar de forma empírica a tabela anterior, se percebe que para poder oferecer um padrão de qualidade decente ao seu povo, não precisa obrigatoriamente ser uma superpotência econômica. É óbvio que caso o país seja rico, os meios para se possibilitar essa qualidade tende a aumentar, mas isso não são vias de regras. Dos países que aparecem no topo da tabela, somente a 
Alemanha compõe o grupo do $G_{7}$, ou seja, o grupo dos setes países mais ricos do mundo. Dos demais países que formam o TOP 5 do IDH, a Austrália está na posição de número 15 e a Suíça na posição de número 19 quanto ao Produto Interno Bruto.

A mesma leitura pode ser feita em relação aos países que compõem o fim da lista no quesito IDH. Dos cinco que apresentam o pior desempenho, nenhum deles aparece com os menores PIBs nos últimos dados disponíveis. Importante mais uma vez ressaltar que devem ser considerados vários fatores, mas o que às vezes deixa transparecer é que as decisões políticas e ideológicas definem a qualidade de vida de um determinado povo.

Ante o exposto, percebe-se que o desenvolvimento humano transcende as questões de ordem econômica, apesar de precisar dela para se efetivar, pois não busca apenas a produção de bens e materiais ou se preocupa em aumentar pura e simplesmente o PIB e a Renda Per Capta de uma nação. Preocupa-se que esses bens e riqueza sejam distribuídos de forma equitativa, capaz de suprir todas as suas necessidades e que possa promover a formação do homem em sua totalidade, evitando grandes desigualdades econômicas, sociais e de renda e que caso o mercado não se autoregule nesse processo, o Estado intervenha no sentido de garantir essa equidade, conforme defende PIKETTY (2014).

\section{Cidades Educadoras}

O desenvolvimento econômico e humano é fundamental para consolidar de vez a qualidade de vida das pessoas. Porém, essas conquistas dificilmente viriam se não fossem construídos pilares para a sustentação dessas políticas. Um dos pilares, porque não dizer o mais importante deles, é a educação. Como afirma FREIRE, "é necessário pensar e executar uma educação que emancipa, uma educação como direito para todos, emancipando o homem em todas as suas esferas”, (2015, p. 14).

Para que a educação de fato seja emancipadora, ela precisa estar no topo das políticas públicas de uma nação. Além disso, como disse GADOTTI (2005, p. 2) ela precisa está acontecendo tanto na modalidade formal, quanto na informal, ou seja, deve ocorrer tanto nos espaços escolares, bem como nos não escolares, precisa está continuadamente atuando no processo de formação do homem.

A educação formal tem objetivos claros e específicos e é representada
principalmente pelas escolas e universidades. Ela depende de uma diretriz
educacional centralizada como o currículo, com estruturas hierárquicas e
burocráticas, determinadas em nível nacional, com órgãos fiscalizadores dos
ministérios da educação. A educação não-formal é mais difusa, menos hierárquica
e menos burocrática. Os programas de educação não-formal não precisam
necessariamente seguir um sistema sequencial e hierárquico de "progressão".
Podem ter duração variável, e podem, ou não, conceder certificados de
aprendizagem. (GADOTTI, 2005, p. 2 )

A escola educa, mas a igreja, a associação dos bairros, a "pelada" no campo da várzea, o xadrez na praça, o motorista no trânsito, a atendente do mercado, o policial na ronda, o médico no hospital, 
entre tantos outros atores são tão importante nesse processo, quanto os professores que estão cotidianamente no chão da escola, GADOTTI (2005, p. 2)

Nesse contexto, desde a década de 90 do século 20, têm surgido movimentos em vários países do mundo para a construção de "Cidades Educadoras". Este movimento começou por Barcelona e desde então tem se espalhado. Um dos conceitos para cidades educadoras é posta por Gadotti da seguinte forma:

Uma cidade pode ser considerada como uma cidade que educa, quando, além de
suas funções tradicionais - econômica, social, política e de prestação de serviços -
ela exerce uma nova função cujo objetivo é a formação para e pela cidadania. Para
uma cidade ser considerada educadora ela precisa promover e desenvolver o
protagonismo de todos e de todas - inclusive das crianças - na busca de um novo
direito, o direito à cidade educadora: "enquanto educadora, a Cidade é também
educanda”.(GADOTTI 2005, p. 6)

Ainda no primeiro encontro para discutir a formação de uma rede de cidades educadoras, foi elaborado um manifesto denominado de "Carta das Cidades Educadoras". Formado inicialmente por 20 metas, houve uma readequação em seu texto para atender aos desafios e as novas demandas sociais no encontro de Bolonha em 1994 e no de Gênova em 2004. A carta expõe na meta 20 uma síntese do que é esperado de uma cidade que almeja ser reconhecida como um espaço de educação.

A cidade educadora deverá oferecer a todos os seus habitantes, enquanto objetivo cada vez mais necessário à comunidade, uma formação sobre os valores e as práticas da cidadania democrática: o respeito, a tolerância, a participação, a responsabilidade e o interesse pela coisa pública, seus programas, seus bens e serviços. (2004, p. 9).

Nessa nova intenção de configuração das cidades para o século 2I, um dos objetivos é que o homem precisa deixar de ser apenas um ser biológico e precisa se apropriar do ser humano, conforme afirma Vygostky (1998, p. 100). Nessa mesma perspectiva Alcoforado (2018, p. 133), afirma que a fala legitima a cidadania humana no processo da construção de uma cidade educadora. Já para Paulo Freire "muito da tarefa educativa implica a nossa posição política e, obviamente, a maneira como exerçamos o poder na Cidade e o sonho ou a utopia de que embebamos a política, a serviço de que e de quem a fazemos" (1993, p. 23).

Nessa perspectiva Freiriana, ao se olhar holisticamente para os fenômenos que tem ocorrido nos últimos anos (desastres ambientais, crescimento das desigualdades, flerte com regimes autoritários, entre outros), percebe-se que ainda há muito que ser feito para que as cidades exerçam de fato o seu papel.

Nesse contexto, a questão da sustentabilidade ( em todos os aspectos possíveis da palavra) é um ponto crucial no processo de construção de uma cidade educadora. Ao se considerar o avanço dos movimentos migratórios, em especial o êxodo rural iniciado no século I9, com o advento da 
Revolução Industrial e se intensificado em todo o mundo no período pós segunda guerra, aliado a ocupação desordenada e sem planejamento das cidades, o subemprego, a mobilidade urbana, dentre outros fatores, tem levantado diversos desafios para que as cidades não consigam exercer minimamente o seu papel.

Diante desses problemas citados no parágrafo anterior, surge na última década um movimento denominado de Cidade Inteligente ou as "Smart Cities", compreendendo como cidade inteligente, aquelas que utilizam tecnologia para gerar eficiência nas operações urbanas, de tal forma que mantém seu desenvolvimento econômico ao mesmo tempo em que melhora a qualidade de vida da população, sendo ainda cidades automatizadas e mais sustentáveis. (CONSTOR, 2019).

Nesse modelo, para uma cidade ser considerada inteligente, é necessário que se promova avanços em seis diferentes áreas, a saber: economia, mobilidade, pessoas, governança, meio ambiente e qualidade de vida. Quando a cidade demonstra capacidade de planejar e executar as melhorias nessas áreas, ao ponto de sua população desfrutar desses bens, ela passa a fazer parte do hall das cidades inteligentes.

O IESE Cities in Motion Strategies analisa todos os anos esses parâmetros e ranqueia as cidades mais inteligentes do mundo. Entre as 25 cidades com melhores pontuações, a Europa se apresenta com 12 cidades e é o continente de melhor desempenho, seguido pela América do Norte, com seis; Ásia, com quatro e Oceania, com três. A cidade brasileira mais bem colocada no ranking é São Paulo na ir6 $6^{a}$ posição. (IESE, 2019). Segue o top ro das cidades mais bem ranqueadas nesses parâmetros do planeta.

Tabela 2 - Ranking das ro cidades mais inteligentes do planeta.

\begin{tabular}{|c|c|c|c|}
\hline Ranking & \multicolumn{1}{c|}{ City } & Performance & CIMI \\
\hline 1 & London - United Kingdom & $\mathrm{H}$ & 100,00 \\
\hline 2 & New York - USA & $\mathrm{H}$ & 94,63 \\
\hline 3 & Amsterdam - Netherlands & $\mathrm{RH}$ & 86,70 \\
\hline 4 & Paris - France & $\mathrm{RH}$ & 86,23 \\
\hline 5 & Reykjavík - Iceland & $\mathrm{RH}$ & 85,35 \\
\hline 6 & Tokyo - Japan & $\mathrm{RH}$ & 84,11 \\
\hline 7 & Singapore - Singapore & $\mathrm{RH}$ & 82,73 \\
\hline 8 & Copenhagen - Denmark & $\mathrm{RH}$ & 81,80 \\
\hline 9 & Berlin - Germany & $\mathrm{RH}$ & 80,88 \\
\hline 10 & Vienna - Austria & $\mathrm{RH}$ & 78,85 \\
\hline
\end{tabular}

Fonte: https://blog.iese.edu/cities-challenges-and-management/2019/05/ro/iese-cities-in-motionindex-2019/

O mito de que grandes metrópoles não conseguem resolver seus gargalos são desmentidos nessa tabela, pois se percebe que entre as dez melhores pontuações, cinco são consideradas cidades 
globais, todas com populações que variam de 2 a 12 milhões de habitantes, portanto, cidades que demandam grandes serviços de moradia, mobilidade, cultura, saneamento básico, emprego, etc.

Importa esclarecer que não necessariamente uma cidade inteligente tenha que ser uma cidade educadora, mas toda cidade que consegue ser educadora, é sem dúvida uma cidade inteligente. Alcoforado (2018) vai mais além nesse entendimento, diz que não é a automatização e robotização que torna uma cidade inteligente, mas sim, o povo que nela habita, através de suas práticas e sentimento de pertencimento, que a tornam. Gadotti (2005), Alcoforado (2018) e Freire (2015), compreendem que esse processo e conquista, devem começar pela apropriação do conhecimento, pela emancipação do saber, por uma educação libertadora, capaz de fazer o homem ser dono de sua própria história e do seu futuro. Em sendo uma cidade educadora e inteligente, isso não ocorre unicamente na escola, mas começa por ela, através de uma educação formal e se consolida fora dela com a colaboração de uma educação informal. (GADOTTI, 2005, p. 2).

Outro ponto a ser observado é que quando uma cidade alcança um status de cidade educadora e inteligente, a priori, ela já resolveu uma série de situações no tocante as questões do desenvolvimento econômico e humano. Sabe-se também que não há uma distribuição homogênea de serviços públicos, bens e riquezas entre seus moradores, mas, o nível de desigualdades entre eles é notoriamente menores. $\mathrm{O}$ acesso a uma série de serviços que permitem que o homem se desenvolva educacional, social e economicamente, credencia esse território a ser um espaço de oportunidades e igualdades.

\section{Conclusão}

Por séculos o homem viveu em situação de precariedade. Isso se deu em parte por migrações forçadas pelas grandes guerras, conquistas de novos territórios, pandemias, desastres naturais, etc. Somado a isso, a lentidão em que se processavam as novas descobertas de tecnologias para o melhoramento da vida humana era um gargalo importante nessa precarização. Somente após o fim da Idade Média, é que esses avanços começaram a se consolidar, ainda assim de forma muito tímida.

No fim do século 19 e início do século 20, já com a segunda revolução industrial em pleno vapor é que se esses problemas começam a ser atenuados. Mas, somente após o período das duas grandes guerras mundiais é que essa tendência de reversão da precariedade da vida humana começa a se consolidar. $\mathrm{O}$ acesso universalizado às vacinas, educação e rede médica, a revolução verde, a implementação do saneamento básico, as conquistas trabalhistas, entre tantos outros avanços, permitiram que o homem vislumbrasse novas possibilidades, entre elas podemos citar a qualidade de vida e a longevidade. 
Essas conquistas serviram de base para que se consolidasse o que se chama hoje de desenvolvimento humano. Um conjunto de bens e serviços que quando acessado, permite que se viva mais e melhor. Por outro lado, é incompreensível que esses bens e serviços, ainda que elementares, não sejam acessados por todos.

Somente através de uma revolução educacional, com acesso universalizado, permanência do aluno na escola e um ensino de qualidade, uma nação pode dá partida em busca de um patamar de desenvolvimento que seja suficientemente capaz de atender aos requisitos básicos da vida humana.

Os direitos citados no parágrafo anterior deveriam ser acessados em qualquer lugar, mas, o advento da urbanização e o esvaziamento do campo acabam por direcionar para as cidades essas atribuições. Assim sendo, são nos espaços urbanos que a garantias desses direitos tendem a se consolidar. Percebe-se esse processo de forma mais sólida nas cidades que optaram por ser um espaço educativo, que se apropriaram dos múltiplos instrumentos espalhados em sua rede para efetivar uma educação que seja capaz de emancipar o homem em todas as suas dimensões, como afirmava Paulo Freire.

Essas cidades educadoras, chamadas também de inteligentes, comprovam que é possível haver crescimento, desenvolvimento e sustentabilidade. Que apesar dos muitos desafios, quando há comprometimento, planejamento estratégico e acima de tudo vontade política, as engrenagens se encaixam e funcionam de forma equilibrada e satisfatória.

\section{Bibliografia}

ALCOFORADO, L.; ABREU, A. C. S. Cidade Educadora: (RE)Pensando Fundamentos Teóricos e Princípios de Organização. Coimbra, Ed. da Universidade de Coimbra, 2018, p. 17 a 35.

AMARO, R. R.: Desenvolvimento - um conceito ultrapassado ou em renovação? Da teoria à prática e da prática à teoria. Cadernos de Estudos Africanos [Online], $4 \mid$ 2003, posto online no dia 25 julho 2014, consultado o 27 janeiro de 2020.

URL : http://journals.openedition.org/cea/1573

BARBOSA, G. S: O Desafio do Desenvolvimento Sustentável.Revista Visões $4^{\underline{a}}$ Edição, №ㄴ 4 , Volume I - Jan/Jun 2008.

CORDEIRO, A. M. R.; AlCOFORADO, L.; FERREIRA, A. G. (Coords.) Territórios, Comunidades Educadoras e Desenvolvimento Sustentável, Coimbra: DG-FLUC, 2014.

FRAZÃO, M. C. P.: As Cidades Educadoras e o Desenvolvimento Local- Caminhar para a Sustentabilidade. Um Estudo de Caso do Município de Leiria - Tese de Doutoramento, UAB, Lisboa, 2017.

FREIRE, P. Política e Educação. Ed. Cortez, São Paulo, 1993.

FREIRE, P.: Pedagogia da Autonomia: Saberes Necessários à Prática Educativa. Ed. Paz e Terra, São Paulo, 2015.

FURTADO, C: O capitalismo Global. Ed. Paz e Terra, Rio de Janeiro, 1999.

GADOTTI, M.; PADILHA, P. R.; CABEZUDO, A.: Cidade Educadora: Princípios e

Experiências. Ed. Cortez, São Paulo, 2004.

GADOTTI, M: Droit à l'éducation: solution à tous les problèmes ou problème sans solution?

Institut International de Droits de L'Enfant (IDE): Sion, Suisse, 2005.

GASPAR, R. C.: A trajetória da economia mundial: da recuperação do pós-guerra aos desafios contemporâneos. Cad. Metrop. [online]. 2015, vol.17, n.33, pp.265-296. 
PIKETTY, T. A Economia da Desigualdade. Editora Intrínseca, Rio de Janeiro, 2014.

SANTOS, M.: Por uma outra globalização: do pensamento único à consciência universal. Ed. Record, Rio de Janeiro, 20or.

SEN, A.: Desenvolvimento como liberdade. Ed. Companhia das Letras, São Paulo, 2000.

\section{Material Acessado da Internet:}

Relatório Anual do Ranking de Desenvolvimento Humano dos Países - IDH.

https://www.br.undp.org/content/brazil/pt/home/presscenter/articles/2019/pnud-apresentarelatorio-de-desenvolvimento-humano-2019-com-dado.html acessado em 20/or/2020.

Relatório das Cidades Inteligentes.

https://blogbrasil.comstor.com/o-que-sao-cidades-inteligentes</a> acessado em 23/or/2020.

Carta das Cidades Educadoras.

http://www.edcities.org/rede-portuguesa/wp-content/uploads/sites/r2/2018/o9/Carta-dascidades-educadoras.pdf acessado em 23/or/2020.

Historiografia das Principais Conferências e Tratados Globais Sobre o Clima.

https://www.nexojornal.com.br/grafico/2017/r1/17/O-hist\% $\mathrm{C}_{3} \% \mathrm{~B}_{3}$ rico-dos-principais-encontrose-acordos-clim\% $\mathrm{C}_{3} \%$ Articos-mundiais acessado em 24/or/2020.

Dados Econômicos sobre os Países.

https://www.focus-economics.com/ acessado em 26/or/2020. 